\title{
Factors Influencing Health INFORMATION SEEKING BEHAVIOUR Among Young Adults In Ucsi UNIVERSITY
}

\author{
Elena. $\mathrm{Ng}$ \\ UCSI University, Malaysia \\ elenangxingyi@gmail.com \\ Rabiah Adawiah, Abu Seman \\ UCSI University, Malaysia \\ rabiah@ucsiuniversity.edu.my \\ Tee, Jing Nee \\ UCSI University, Malaysia \\ jingnitee@gmail.com
}

\begin{abstract}
The internet has been recognized as one of the common health-seeking platforms that widely used to maintain physical and mental wellness. Malaysian internet users make use of the connection to obtain as their fundamental basis for a lifestyle change and to meet the different needs, especially young adults who grown up in this technology era. There is little or limited research conducted particularly on young adult's health information-seeking behavior. The objective of this study is to determine the underlying factors influencing the utilization of the internet for information seeking in the context of health among young adults in Malaysia. A total of 370 private university young adults were chosen conveniently to take part in this quantitative research. The research objectives were examined with the theoretical support of the Health Belief Model (HBM) and Technology Acceptance Model (TAM). The major findings of this study indicate that health consciousness, perceived severity, perceived susceptibility, and perceived usefulness were influencing factors that empower young adults to seek digital health information. Furthermore, integration of the HBM and TAM framework is applicable for the study of health information-seeking behavior among young adults. It is high time for healthcare providers to promote preventive behavior and provide credible health information on the internet due to the positive attitude towards health among young adults. Limitations and suggestions for future research were discussed in this paper.
\end{abstract}

Keywords: Technology Acceptance Model, health information seeking, young adults, Health Belief Model 


\section{INTRODUCTION}

The improvement of technology has resulted in many significant impacts in every aspect of our lives, from the way we communicate to the way we acquire resources and information. As compared to the past centuries, technology today contributed a lot in revamping the way we interact with the community across the globe. Mobile health (mHealth) is developed where people using electronic devices (such as gadgets, mobile phones, websites) to serve as an effective tool in collecting health information in a fast and low-cost way (Marcolino et al., 2018). The term "information seeking" is defined as how people seek, need, and use information differently. Examples of the usage of the internet include communication, entertainment, obtaining information, and social networking (Robson \& Robinson, 2015). According to the Malaysian Communication and Multimedia Commission (2017), a survey on internet usage in Malaysia stated that $77.2 \%$ of Malaysian do health information seeking. The information that individuals found empowers the decision on their physical and mental wellness (Jamal et. al., 2015). In other words, people can make a better-informed decision in every aspect of their life, which includes their health, through information-seeking behaviour. As technology rapidly progressing, the internet has become an essential element of our lives and has been recognized as one of the common communication tools that we used for information seeking to meet different needs.

The internet has been recognized as one of the common health-seeking platforms that widely used to maintain physical and mental wellness. The majority of the internet users in Malaysia especially young adults identify the internet as a fundamental basis for a lifestyle change and to meet the different needs. A study revealed that a variety of behavior is being displayed by the user as they are looking for the information to meet different needs (Orlu et al., 2016).

The role of health information seeking is vital among young adults although they often have low empowerment in deciding for their body condition and health care (Beck et al., 2014). The health information-seeking behaviour leads to an adoption of healthy lifestyles among young adults by educating and motivating them to maintain their welfare, encouraging them to seek social support, and establishing good nutrition habits into their daily meals (Mills \& Todorova, 2016; Musaiger et al., 2014; Osei Asibey et al., 2017; Wong et al., 2014).

In Malaysia, young adults constitute approximately $20 \%$ of the general population (CIA World Factbook, 2020) who are the potential future leaders of Malaysia and should not be neglected. Education and knowledge are important aspects in their lives that provide a strong foundation in preparing themselves for the future. However, the health awareness among Malaysian, especially young adults, is still relatively poor and low (Mansor \& Harun, 2014). Despite there is a rise in digital health use, the death rates in Malaysia revealed a $4.7 \%$ increase as compared to the year 2017 and mainly caused by non-communicable diseases (Department of Statistic Malaysia, 2018). This indicated that although the internet provides easy access to information, health awareness in Malaysia still needs to be improved. In terms of health information seekers, there was little or limited research conducted particularly on young adults who grow up in this technology era, where everything is easy-accessible at their fingertips.

Regarding theoretical framework for health communication study, limited empirical have utilised Health Believe Model (HBM) to explore the media and communication aspect of healthcare, such as health information-seeking behaviour through the internet (Jones, Jensen, Scherr, Brown, Christy \& Weaver, 2015). Other than that, limited studies have integrated both theories or models from public health that is HBM, and media that is Technology Acceptance 
Model (TAM) (Ahadzadeh, Sharif, Ong \& Khong, 2015; Ahadzadeh, Sharif \& Ong, 2018; Marton \& Choo, 2012). Most studies have utilised theory from a single field of study such as public health (Darteh, Kumi-Kyereme, and Awusabo-Asare, 2016; Jabson, Patterson \& Kamen, 2017; Lau, Gross, Wu, Cheng \& Lau, 2017; Robison-Chadwell, 2017), or media alone (Ahmad \& Khan, 2017; Chang \& Im, 2014; Sheng \& Simpson, 2015) to study the health informationseeking behaviour. Hence, it is essential to explore the impact of health-related factors (health consciousness, perceived severity, perceived usefulness, and perceived susceptibility) towards the health information seeking as it provides a more robust understanding of the influential effect of these antecedents among the young adults, integrating both HBM (HBM; Davis, 1989) and TAM (TAM; Glantz et al., 2002, p. 52).

This study aims to explore the factors that influence health information seeking among young adults in Malaysia. Figure 1 demonstrates the direct relation of each variable towards internet usage for health information seeking. It was hypothesised that: (i) there is a significant correlation between health consciousness and the internet usage for health information seeking among young adults; (ii) there is a significant correlation between perceived severity and the internet usage for health information seeking among young adults; (iii) there is a significant correlation between perceived susceptibility and the internet usage for health information seeking among young adults; (iv) there is a significant correlation between perceived the usefulness and the internet usage for health information seeking among young adults.

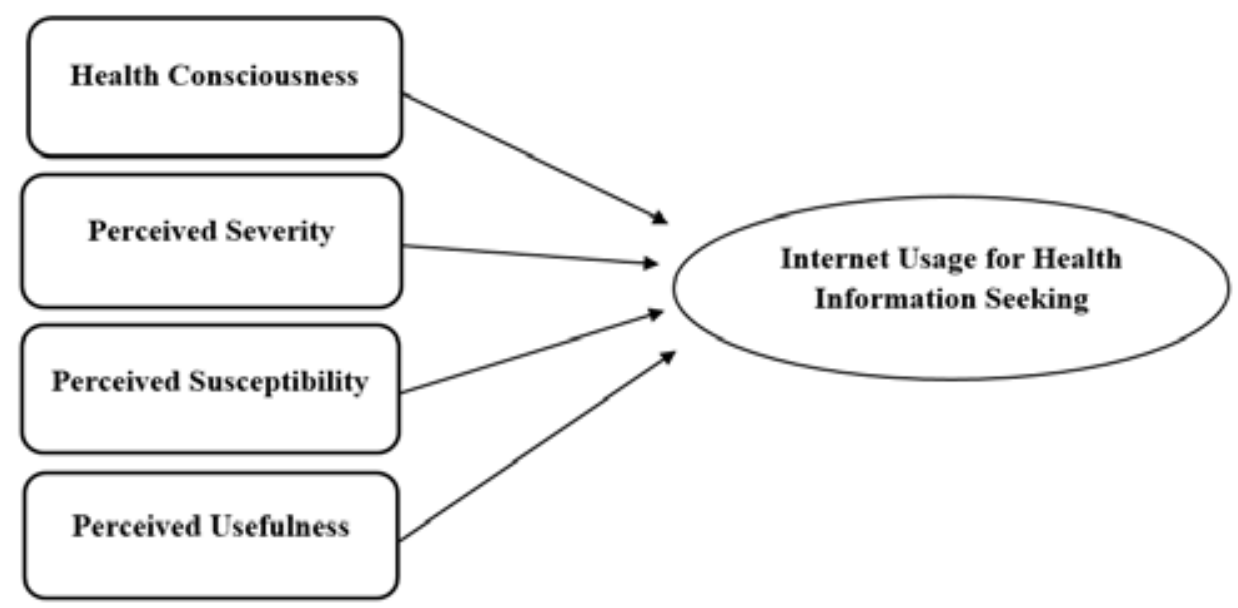

Figure 1: Conceptual framework

\section{LITERATURE REVIEW}

Last year, the Department of Statistic Malaysia (DOSM) has released its report on the causes of death among our citizens. In their report, DOSM (2017) emphasized and stated health issues as one of the major causes of death among Malaysians. The report concluded that "the major killers of death in 2016 are the ischaemic heart diseases with $13.2 \%$, pneumonia $(12.5 \%)$, cerebrovascular diseases $(6.9 \%)$, transport accidents $(5.4 \%)$ and malignant neoplasm of trachea, bronchus and lung with 2.2\% " (Department of Statistic Malaysia, 2017). Apparently, in 2016, approximately 162,201 deaths were documented and this figure is rising from 2015. 
According to the internet user survey in Malaysia, the Malaysian Communication and Multimedia Commission (2017) reported that the usage of smartphones for internet services among Malaysian continues to climb and remained prominent in the market over the years as compared to other communication tools. Meanwhile, smartphones are becoming more prominent to Malaysian students as they rely heavily on them for communication, information seeking, and social networks (Suki, 2013). Among the smartphone application used to easily access health information is mobile health (mHealth). MHealth has a significant impact on health awareness among young adults (Zahra et al., 2016).

DOSM released an abridged life table which stated that "Malaysia's population are accustomed to live up to 74.8 years (72.7 years for male, 77.4 years for female) and this figure has been rise up by 0.6 years since 2011" (Department of Statistic Malaysia, 2017). Health status is the indicator for online health information seeking among Malaysian citizens (Muhamad, Afshari \& Mohamed, 2011). Users actively engaged in health information seeking on the webpage or website when they have high hope in improving their health status to gain a higher level of satisfaction on their health condition. However, healthcare delivery in the rural setting remains one of Malaysia's challenges, as stated by (Thomas, Beh \& Nordin, 2011).

\section{Conceptual Framework}

This study integrated TAM and HBM to explore the health-related factors that influence health information seeking among young adults in Malaysia. Two independent variables (perceived susceptibility and perceived severity) were adopted from Health Belief Model (HBM) by Hochbaum et al. (1952). Meanwhile, variables perceived usefulness and internet usage for health information seeking were adopted from previous research by Davis (1989). The health information-seeking behaviour was adopted from variable behaviour intention in TAM. Additionally, another independent variable has been added into the framework that is health consciousness (Ahadzadeh et al., 2018).

- Technology Acceptance Model (TAM).

TAM was developed to determine young adult's reactions towards the adoption of a new learning system (Davis, 1989). The framework of this model was initially used to enhance the technology acceptance for organizational performance improvement (Davis, 1989, p.320). However, Davis then added two determinants to the model, namely perceived usefulness (PU) and perceived ease of use (PEOU), into his model. In this context, PU is defined as the "degree to which a person believes that using particular technology would enhance his/her performance on a task" (Davis, 1989, p. 320) while PEOU is defined as "the degree to which a person believes that using a particular system would be free from effort" (Davis, 1989, p. 320). With the additional variables, TAM explains the technology usage established by behavioural intention and the attitude towards the technology. Both behavioural intention and attitude are influenced by PU and PEOU.

- Health Believe Model (HBM).

HBM was first introduced in the 1950s by Hochbaum, Rosenstock, and Kegels (1952); aims to predict health-related behaviour using social psychological factors (Rosenstock \& Irwin (1974). An individual's perception of their health, seriousness, benefits, and barriers of their action, and self-efficacy activate their health behaviour engagement. 
HBM assumes that the patient is less likely to take health-related actions such as seeking health information, do a medical check-up, engaging in physical activities when there is no sign of symptom or illness (Jones et al., 2015). In this case, health information seeking can be considered as one of the health-related actions and the "particular alternative" can be considered as the use of online communication tools for health information seeking that bring changes to consumer's behaviour. There are five factors of health behaviour in this model, they are health motivation, perceived severity, perceived susceptibility, perceived benefits, and perceived barriers (Glanz, Rimer \& Viswanath, 2008).

\section{Health Consciousness}

DiPietro et al. (2016) defined health consciousness as "the degree to which one's concern about health is incorporated into their personal lives". An individual who receives higher education is more likely to gain more knowledge about their health condition on the internet (Chae \& Quick, 2014). The research of Ahadzadeh et al. (2018) found that conscious women are more likely to expose themselves to the internet to obtain information relevant to health. This indicates that high health-conscious leads to a high frequency of internet usage on retrieving health information (Ahadzadeh et al., 2018). From this, a hypothesis has been formulated:

- H1: There is a significant correlation between health consciousness and internet usage for health information seeking among young adults.

\section{Perceived Severity}

Perceived severity is defined as "the act of perceiving that one individual is at risk of getting a disease" (Crosby et al., 2014). A greater perceived severity leads to the rise in health informationseeking behaviour (Ahadzadeh et al., 2018; Robison-Chadwell, 2017). In other words, people with low perceived severity about their health status commonly have low health informationseeking behaviour (Park et al., 2014; Suggs, Cowdery \& Noll, 2010). In some situations such as immunisation, the perceived severity of contracting any virus is important to improve an individual's readiness for immunisation. This readiness is improved through knowledge acquisition which can be done through the internet (Painter, Plaster, Tjersland, \& Jacobsen, 2017; Plaster, Painter, Tjersland \& Jacobsen, 2018). Based on the literature, the following hypothesis is proposed:

- H2: There is a significant correlation between perceived severity and internet usage for health information seeking among young adults.

\section{Perceived Susceptibility}

Perceived susceptibility (PS) refers to a "human's knowledge and perception on his or her susceptibility towards certain illness" (Twigg \& Byrne, 2015). Perceived susceptibility to one's health problem is known as one of the key variables of HBM (Darteh et al., 2016). An increased perceived susceptibility leads to the high rate of health information seeking and the incidental exposure to health information (Jabson, Patterson \& Kamen, 2017; Thackeray, Crookston \& 
West, 2013). Hence, boost an individual's health awareness (Joseph, Burke, Tuason, Barker and Pasick, 2009). Individuals who perceived that they are not in danger of being diagnosed with an illness, are less motivated to access the internet for health information and to improve one's health condition (Suggs, Cowdery \& Noll, 2010). In the worst-case scenario, perceived susceptibility may lead to internet addiction (Lau et al., 2017). This addiction is more likely to occur among male students where they spend more time surfing the internet, playing online video games, and obtaining information on the internet. In contrary to previous studies, perceived susceptibility among pregnant women in Iran did not influence them towards performing health behaviour including utilising antenatal care facilities (Parsa, Besharati, Haji Maghsodi, Afshari \& Emdadi, 2018). The lack of facilities utilisation is due to the lack of knowledge on the importance of antenatal care. These women may be lack of exposure to antenatal care information that can be easily obtained from the internet. To summarise these, a hypothesis is proposed:

- H3: There is a significant correlation between perceived susceptibility and internet usage for health information seeking among young adults.

\section{Perceived Usefulness}

Perceived usefulness is commonly interpreted as the utilization of certain electronic instruments that are beneficial for one's improvement of health condition(Davis, 1989). Perceived usefulness acts as one of the predictors that motivate users to surf the net to obtain health data (Lemire et al. as cited in Sinclaire et al., 2018). With the use of seeking information online for well-being, individuals can have better management for their health by joining a fitness club, attending swimming class, and looking for workout instructions to build muscles and gain a perfect body (Gray, Klein, Noyce, Sesselberg \& Cantrill, 2005). Ninety-seven percent of the young users utilize health data from the famous search engine "Google" to manage their physical and mental well-being, as they perceived that using Google will bring benefits to their friend and peers' health (Senkowski \& Branscum, 2015). However, individual's faith in their healthcare providers can be reduced due to the advancement and usefulness of the internet in retrieving important sources to manage their care (Audrain-Pontevia \& Menvielle, 2018). A higher level of trust and information surfing on the web will likely reduce the frequency of doctor visits. Therefore, a hypothesis has been proposed:

- H4: There is a significant correlation between perceived usefulness and internet usage for health information seeking among young adults.

\section{Internet Usage for Health Information Seeking}

Health information-seeking behaviour can be defined as the way users retrieving information regarding one's health condition e.g.: 'sickness, 'symptoms' and 'risk' preventing it from becoming chronic (Mills and Todorova, 2016). The internet today can be seen as a platform which a load of sources, also convenient and easy for a user to access health information (Ahadzadeh et al., 2015). The Internet has proven to be the best platform to ask questions and find an answer on any topic such as health. The users with mutual illness may actively participate in online forums to exchange views and opinions to identify better solutions in overcoming health issues. 


\section{METHODOLOGY}

In this study, the quantitative method was selected as it is more suitable to address the association between dependent variables and independent variables. Besides, the data and results obtained are based on the huge sample size.

\section{Measurement}

This study used questionnaires to collect its data. There are three sections in the questionnaire beginning with the demographic profile. The second section of the questionnaires includes Health Consciousness, Perceived Severity, Perceived Susceptibility, Perceived Usefulness (see Table 1). Finally, the third section of the questionnaire focused on the dependent variable that is The Internet Usage for Health Information Seeking (see Table 1). The items for each sub-section were fully adopted from previous studies.

\section{Table 1: Details of Adopted Items in Questionnaire}

\begin{tabular}{|c|c|c|}
\hline Variable & Operational definition & Sample item \\
\hline $\begin{array}{l}\text { Health } \\
\text { consciousness }\end{array}$ & $\begin{array}{l}\text { It was measured using } 4 \text { items adopted from } \\
\text { Oude Ophuis (1989). }\end{array}$ & $\begin{array}{l}\text { "I have the impression that I } \\
\text { sacrifice a lot for my health." }\end{array}$ \\
\hline $\begin{array}{l}\text { Perceived } \\
\text { severity }\end{array}$ & $\begin{array}{l}\text { It was measure using } 4 \text { items adapted from } \\
\text { Kim \& Park (2012). }\end{array}$ & $\begin{array}{l}\text { "I am afraid of facing attack } \\
\text { or deterioration of chronic } \\
\text { diseases." }\end{array}$ \\
\hline $\begin{array}{l}\text { Perceived } \\
\text { susceptibility }\end{array}$ & $\begin{array}{l}\text { It was measured using } 5 \text { items adopted from } \\
\text { Bryan, Aiken and West (1997), and Kim and } \\
\text { Park (2012). }\end{array}$ & $\begin{array}{l}\text { "There is a great chance that } \\
\text { I will be exposed to a chronic } \\
\text { disease" }\end{array}$ \\
\hline $\begin{array}{l}\text { Perceived } \\
\text { usefulness }\end{array}$ & $\begin{array}{l}\text { It was measure using } 4 \text { items adopted from } \\
\text { Davis (1989). }\end{array}$ & $\begin{array}{l}\text { "Using the Internet for health } \\
\text { information is useful in } \\
\text { managing my daily health." }\end{array}$ \\
\hline $\begin{array}{l}\text { Internet usage } \\
\text { for health } \\
\text { information } \\
\text { seeking }\end{array}$ & $\begin{array}{l}\text { It was measure using } 6 \text { items adopted Hale et } \\
\text { al. (2010), Kim and Park (2012), and Yoo and } \\
\text { Robbins (2008). }\end{array}$ & $\begin{array}{l}\text { "I use the Internet to get } \\
\text { general health information." }\end{array}$ \\
\hline
\end{tabular}

\section{Reliability Tests for Variables}

A reliability test was carried out and the value of Cronbach's alpha for each variable was presented in Table 2. The Cronbach's alpha values which over .90 are viewed as excellent, values which over .80 are considered good, values over .70 are considered acceptable, values over .60 are viewed as questionable, and values around .50 and below are considered poor and unacceptable respectively (Taber, 2018). Overall, all measurements presented an adequate to a satisfactory level of reliability. 
Table 2: Cronbach's alpha for variables

\begin{tabular}{lll}
\hline Variable & Cronbach's alpha & Number of items \\
\hline Health consciousness & 0.60 & 4 \\
Perceived severity & 0.90 & 4 \\
Perceived susceptibility & 0.78 & 5 \\
Perceived usefulness & 0.89 & 4 \\
Internet usage for health information seeking & 0.86 & 6 \\
\hline
\end{tabular}

\section{Participants and Sampling}

Respondents consisted of Malaysian young adults who have enrolled students and pursuing their studies in the leading multinational institution, UCSI University. The multistage sampling method was adopted in this study. UCSI University is a multinational institution with 3 branches located in different states; Sarawak, Terengganu, and Kuala Lumpur. Through the first stage that is cluster sampling, the Kuala Lumpur branch was selected to conduct this study. With wide varieties of races, religions, and cultural, this provides a vast number of perspectives and vast viewpoints on this study.

Next sampling stage, convenience sampling was used. Based on past studies, Malaysian young adults were known as the most active health information seekers, educated, and mostly living in highly populated urban areas such as Kuala Lumpur. Thus, UCSI University undergraduate students were chosen to take part in this quantitative research. Data was collected through questionnaire distribution using the drop-collect method. Participants were given 5-7 minutes to complete the questionnaire.

There were only a total of 136 male respondents $(36.8 \%)$ and more than half were female with 234 respondents (63.2\%). Out of 370 respondents, only 7 of them were 27 and above. The majority of the respondent, $216(58.4 \%)$ are between 21 to 23 years old. Another $120(32.4 \%)$ and $27(7.3 \%)$ respondents are from an age range of 18-20 and 24-26 years old. In terms of ethnicity, most of the respondents are Chinese; 279 (75.4\%), followed by the Indian ethnic group $34(9.2 \%)$ respondents and other ethnic group are $50(13.5 \%)$ respondents. Out of 370 respondents, the smallest group is Malay that is $7(1.9 \%)$ respondents. Most respondents are single $(83.2 \%)$, while $1.9 \%$ are married. A total of $50(13.5 \%)$ respondents are in a committed relationship, $5(1.4 \%)$ out of 370 respondents did not reveal their marital status in the questionnaire.

\section{Data Analysis}

The data was gathered and keyed into the SPSS to test the correlation between health-related factors and internet usage for health information seeking. In this study, descriptive analysis is used to study participants' demographic, and Pearson Correlation is used to test the hypothesis set for this study. 


\section{FINDINGS}

The first variable; health consciousness reported an average mean of $3.67(S D=0.81$ ) out of 5 points by the respondents. Second, the average mean for perceived severity is $3.73(\mathrm{SD}=0.87$ ), which is the highest among all variables. the average mean for the third variable perceived susceptibility is $2.85(\mathrm{SD}=1.07)$. Forth, the average mean for variable perceived usefulness is score $3.64(S D=0.79)$ out of 5 points by the respondents. Lastly, the overall mean for variable internet usage for health information seeking is $3.73(\mathrm{SD}=1.32)$, which is also the highest variable among the five variables in this study

\section{Hypothesis 1}

Based on the results shown in Table 3 , there was a positive significant relationship between the two variables $(r=0.222, n=370, p<0.05)$, this indicated that when health consciousness increases, the internet usage for health information seeking increases. Out of 370 participants surveyed, $88.7 \%$ of them agreed and strongly agreed that it is substantial to know well how to practice good eating habits. Not to mention, a health-conscious person is more cognizant of what they consume daily, actively looks up for important sources related to health via the internet, and constantly questions their decision and consumption to maintain mental and physical wellness. Therefore, health consciousness does bring a significant impact to the frequency of internet usage for health information seeking. Hypothesis 1 was accepted.

Table 3: Pearson Correlation test between health consciousness and internet usage for HIS $(n=370)$

\begin{tabular}{lccc} 
& \multicolumn{3}{c}{ Internet Usage for HIS } \\
& $r$ & Sig. Value $(p)$ & H1 \\
Health Consciousness & 0.22 & 0.000 & Accepted \\
\hline
\end{tabular}

Note: HIS = Health Information Seeking; H1: There is a significant correlation between health consciousness and internet usage for health information seeking among young adults.

\section{Hypothesis 2}

Table 4 , reveals a positive significant association between perceived severity and internet usage for health information seeking $(r=0.159, n=370, p<0.05)$. Based on Guildford's "rule of thumb", the result $r=0.159$ indicating a very weak correlation between the two variables, which results in Hypothesis 2 was accepted. It can be concluded that youth adults are afraid of harbouring health diseases, as they tend to think that it might bring numerous obstacles to all aspects of their life. For example, a total of $76.3 \%$ of the participants revealed that poor health conditions and health status affecting workforce productivity, which influences their working performance with a low quantity of output in the working industry. Hence, young adults are motivated to seek online health information and solutions for health management when perceived severity is taking into account, to avoid facing resultant problems in long term. 
Table 4: Pearson Correlation test between perceived severity and internet usage for HIS $(n=370)$

\begin{tabular}{lccc} 
& \multicolumn{3}{c}{ Internet Usage for HIS } \\
& $r$ & Sig. Value $(p)$ & H2 \\
Perceived Severity & 0.16 & 0.002 & Accepted \\
\hline
\end{tabular}

Note: HIS = Health Information Seeking; H2: There is a significant correlation between perceived severity and internet usage for health information seeking among young adults.

\section{Hypothesis 3.}

Based on the results demonstrated in Table 5, there was a positive significant relationship between the two variables $(r=0.131, n=370, p<0.05), p=0.012$ indicates that when "perceived susceptibility" increases, the internet usage for health information seeking rises. The result $r$ $=0.131$ explains the weak level of correlation according to Guilford's (1973) "Rule of Thumb". Therefore, the "perceived susceptibility" variable does impact the significant rate of internet usage for health information seeking. Hypothesis 3 was accepted. Out of 370 participants surveyed, $33 \%$ of them agreed and strongly agreed that they are vulnerable to certain complex health diseases. Not to mention, most young adults are aware that failure to maintain good daily habits will put them at risk of harbouring harmful diseases. On the other hand, our findings can conclude that young adults exposed themselves to all sorts of online information when they think they are having a high possibility of contracting certain health issues.

Table 5: Pearson Correlation test between perceived susceptibility and internet usage for HIS $(n=370)$

\begin{tabular}{lccc} 
& \multicolumn{3}{c}{ Internet Usage for HIS } \\
Perceived Susceptibility & $r$ & Sig. Value $(p)$ & H3 \\
\hline
\end{tabular}

Note: HIS = Health Information Seeking; H3: There is a significant correlation between perceived susceptibility and internet usage for health information seeking among young adults.

\section{Hypothesis 4.}

The result from Pearson correlation indicates that perceived usefulness $(r=0.590, n=370, p$ $<0.05)$ is significant to the internet usage for health information seeking. Looking at Table 6 , the p-value for "Perceived Usefulness" $(p=0.000)$ is less than 0.05 , thus, it influences the internet usage for health information in a way. According to Guilford's (1973) "rule of thumb", the result $r=0.590$ indicates that there is a moderately strong correlation between these two variables. In conclusion, when perceived usefulness increases, the internet usage for health information seeking will increase. Hypothesis 4 was accepted. 


\section{Table 6: Pearson Correlation test between perceived usefulness and internet usage for HIS $(n=370)$}

\begin{tabular}{lccc} 
& \multicolumn{3}{c}{ Internet Usage for HIS } \\
& $r$ & Sig. Value $(p)$ & H4 \\
Perceived Usefulness & 0.59 & 0.000 & Accepted \\
\hline
\end{tabular}

Note. HIS = Health Information Seeking; H4: There is a significant correlation between perceived usefulness and internet usage for health information seeking among young adults.

\section{DISCUSSION}

The first hypothesis has been accepted, where young adults who are concerned about their health tend to be more aware of the food they consume every day. Food consumption should be beneficial to them in maintaining a healthy eating lifestyle. In other words, young adults who have the ideal perception of the seriousness of complex diseases are more likely to enhance their knowledge and skills on coping with health issues to avoid resultants problem such as financial, sexual, and social problem that chronic diseases might cause (Zhou \& Krishnan, 2018). As a result, when health consciousness increase, internet usage for health information seeking will increase. Contrary to the findings of Zhou and Krishnan (2018), they have found that American youths' level of health consciousness does not bring a positive impact on their health conditions.

The second hypothesis on the significant correlation of perceived severity and health information seeking is supported by past studies (McWhirter \& Hoffman, 2016; Park et al., 2014). Based on the findings, it can be concluded that young adults are generally cautious of non-communication diseases. They believe that the severity of chronic diseases may affect the personal relationship with their partner, peer, and family. Perceived severity was found to be the main predictors which influence the consumer's decision-making and behaviour particularly towards engagement in skin cancer prevention (McWhirter \& Hoffman, 2016). Individuals who have low perceived severity towards any sickness tend to have low intention to seek health information (Park et al., 2014). Hence, perceived severity is one of the predictors that directly affect young adults' attitude towards the act of pursuing health information using digital technologies.

Based on the acceptance of the third hypothesis, perceived susceptibility was found to have a significant impact on Internet usage to obtain health sources. The results are in line with previous studies (Suggs et al., 2010; Valera et al., 2018; Yin et al., 2018) which indicated that high perceived susceptibility results in a high frequency of digital usage for health information seeking. Perceived susceptibility is taken into account when individuals are worried and feel threatened regarding their health conditions, which in turn a rise in utilisation of the internet (Valera et al., 2018; Yin et al., 2018). Hence, perceived susceptibility may also result in an addiction to internet usage due to high information-seeking activity through the internet (Lau et al., 2017).

Moreover, the result revealed that perceived usefulness has the strongest correlation with internet usage for health information seeking as compared to other health factors. Past research showed that more than half of young adults possess health information via the world wide web, basically for "personal use", "curiosity" and one's knowledge learning (Ahadzadeh 
et al., 2015; De Angelis et al. 2018; Basch et al., 2018; Li et al., 2018; Montagni et al., 2018). Perceived usefulness is considered when exposure to online information is advantageous in decision making and applicable to manage self-care. Therefore, higher perceived usefulness leads to higher internet usage to seek for solutions to manage their daily health and decision making to resolve the health problems they faced.

Overall, our findings provide a better insight on how perceived severity, perceived usefulness, health consciousness, and perceived susceptibility directly or indirectly bring an impact on internet usage for health information seeking among young adults. The four main health-related factors act as the predictors which empowering young adults to possess digital health sources from the World Wide Web. Young adults are widely known as the most active information seekers, they frequently turn to the internet searching for solutions and answers to fill the gaps between what they already know and what they need to know.

\section{Implications}

Theoretically, this study proposes a health information seeking research framework with the combination of both HBM and TAM. This framework validates the outcome of perceived severity, perceived susceptibility, perceived usefulness, and health consciousness on internet usage for health information seeking through a quantitative study. Furthermore, our study extends the HBM and TAM research, affirming the important role of health-related factors on information seeking via the internet. Besides, both theories are applicable particularly in the Malaysian context, proven that both can be used in health behaviour research to have an amalgamation of health and technology perspectives which provide a broader scope to better understanding this study in the context of health.

For the practical implications, the results of this study provide a better insight to individuals, health professionals, and providers, health institutions particularly in health communication field, with the act of implying the importance of seeking information online for health management. With the knowledge particularly on the underlying factors resulting health information seekers actively hunt for information via the internet, health providers could take this golden opportunity to come out with a health care website or a web page which loaded with all sort of informative and trustworthy sources, aiming to have a growth in web traffic promoting the importance of self-health management to the public, especially among the young adults. The internet technologies savvy, especially young adults would be motivated to engage themselves in seeking high-quality health sources disseminated through the website to manage their care. Besides that, abundant health campaigns and activities should be carried on to create awareness, particularly in educational institutions and universities, to enhance young adults' health literacy and enlighten their capability of dealing with complex health diseases. There is also a good chance to develop mobile health applications which promote the importance of maintaining a healthy lifestyle, changing individual's perception on health management and encouraging users to have preventive behaviour instead of being a passive information seeker. In terms of the availability of healthcare access, the amalgamation of mobile applications and the internet could be beneficial to society, especially young adults to possess high-quality health information for one's health management. 


\section{Limitation and future suggestions.}

Not to mention, there are several limitations in this study. First, as compared to previous studies, most research has a minimum of 500 participants. Meanwhile, the sample size in this study is considered small and limited with only 370 students which will affect the accuracy of the results. On the other hand, the main targeted young adults are mainly students from UCSI University, which is inappropriate to represent the Malaysian young adults as a whole. Therefore, future researchers are suggested to broaden the study area and scope by including more public and private education institutions to obtain a more comprehensive and generalize outcome. Second, aside from perceived usefulness, perceived severity, and perceived susceptibility variables tested in this study, many other underlying health factors were not selected. For future studies, environmental, income level, family background, and health status may be added as a predictor to internet usage for health information seeking. Third, the types of research design used can be one of the limitations. Applying the quantitative method in this study allowed the researcher to acquire a huge quantity of data however the results obtained are superficial. Thus, the qualitative method should be taken into account to acquire in-depth information from participants to better comprehend young adults' attitudes towards the use of communication technology for health support.

\section{CONCLUSION}

Overall, our findings provide a better insight on how perceived severity, perceived usefulness, health consciousness, and perceived susceptibility directly or indirectly bring an impact on internet usage for health information seeking among young adults. The four main healthrelated factors were appropriate to act as the predictors which empowering young adults to possess digital health sources from the World Wide Web. Young adults are widely known as the most active information seekers, they frequently turn to the internet searching for solutions and answers to fill the gaps between what they already know and what they need to know. However, this research suggests health education institutions should put the effort into educating young adults to practice preventive behavior instead of being passive information seekers, as failure to apply the knowledge and skills retrieved from the internet to their daily lives will not improve one's health condition. In summary, this research substantially demonstrated that young adults with perceived severity, health-conscious, perceived usefulness, and perceived susceptibility carry out more health information seeking via the internet.

\section{REFERENCES}

Ahadzadeh, A. S., \& Sharif, S. P. (2017). Online health information seeking among Malaysian women: Technology acceptance model perspective. The Journal of the South East Asia Research Centre for Communications and Humanities, 9 (1), 47-70.

Ahadzadeh, A. S., Sharif, S. P., \& Ong, F. S. (2018). Online health information seeking among women: the moderating role of health consciousness. Online Information Review, 42 (1), 58-72. https://doi.org/10.1108/oir-02-2016-0066

Ahadzadeh, A. S., Sharif, S. P., Ong, F. S., \& Khong, K. W. (2015). Integrating health belief model and technology acceptance model: An investigation of health-related internet use. Journal of Medical Internet Research, 17 (2), e45. https://doi.org/10.2196/jmir.3564 
Ahmad, A., Khan, M. N. (2017) Students Seeking Health-related Information over Internet: An Empirical Study. Journal of Health Management, 19(2), 352-367. https://doi. org/10.1177/0972063417699720

Audrain-Pontevia, A. F., \& Menvielle, L. (2018). Effects of interpersonal trust among users of online health communities on patient trust in and satisfaction with their physician. International Journal of Technology Assessment in Health Care, 34 (1), 56-62.

Basch, C. H., MacLean, S. A., Romero, R. A., \& Ethan, D. (2018). Health information seeking behavior among college students. Journal of community health, 43(6), 1094-1099.

Beck, F., Richard, J., Nguyen-Thanh, V., Montagni, I., Parizot, I., \& Renahy, E. (2014). Use of the internet as a health information resource among french young adults: Results from a nationally representative survey. Journal of Medical Internet Research, 16(5), e128. https://doi.org/10.2196/jmir.2934

Bryan, A. D., Aiken, L. S., \& West, S. G. (1997). Young women's condom use: The influence of acceptance of sexuality, control over the sexual encounter, and perceived susceptibility to common STDs. Health Psychology, 16(5), 468.

Chae, J., \& Quick, B. L. (2014). An examination of the relationship between health information use and health orientation in Korean mothers: Focusing on the type of health information. Journal of Health Communication, 20 (3), 275-284. https://doi.org/10.1080/10810730.2014. 925016

Chang, S. J. \& Im, E-O. (2014). A path analysis of internet health information seeking behaviors among older adults. Geriatric Nursing, 35 (2), 137-141. https://doi.org/10.1016/j. gerinurse.2013.11.005

Chen, M. F., \& Lin, N. P. (2018). Incorporation of health consciousness into the technology readiness and acceptance model to predict app download and usage intentions. Internet Research, 28 (2), 351-373.

CIA World Factbook. (2020). Malaysia Demographics Profile. Indexmundi.https://www. indexmundi.com/malaysia/demographics_profile.html.

Crosby, R. A., Milhausen, R. R., Graham, C. A., Yarber, W. L., Sanders, S. A., Charnigo, R., \& Shrier, L. A. (2014). Likelihood of condom use when sexually transmitted diseases are suspected. Health Education $\mathcal{E}$ Behavior, 41(4), 449-454. https://doi. org/10.1177/1090198114529588

Darteh, E. K., Kumi-Kyereme, A., \& Awusabo-Asare, K. (2016). Perception of risk of HIV among adolescents' living in an urban slum in Ghana. African Journal of Reproductive Health, 20 (1), 62-70. https://doi.org/10.29063/ajrh2016/v20i1.6

Davis, F. (1989). Perceived usefulness, perceived ease of use, and user acceptance of information technology. MIS Quarterly, 13(3), 319-340.

De Angelis, G., Wells, G. A., Davies, B., King, J., Shallwani, S. M., McEwan, J., ... \& Brosseau, L. (2018). The use of social media among health professionals to facilitate chronic disease self-management with their patients: A systematic review. Digital health, 4, 2055207618771416.

Department of Statistic Malaysia. (2017, October 31). Statistics on Causes of Death, Malaysia, 2017. Department of Statistics Malaysia. https://www.dosm.gov.my/v1/index. php? $r=$ column/cthemeByCat\&cat=401\&bul_id=Y3p sYUI2VjU0ZzRhZU1kcVFMMTh GUT09\&menu_id=L0pheU43NWJwRWVSZklWdzQ 4TlhUUT09 
Department of Statistic Malaysia. (2018, October 31). Statistics on Causes of Death, Malaysia, 2018. Department of Statistics Malaysia. https://www.dosm.gov.my/v1/index. php?r=column/pdfPrev\&id=aWg2VjJkZHhYcDdEM 3JQSGloeTVlZz09

DiPietro, R. B., Remar, D., \& Parsa, H. G. (2016). Health consciousness, menu information, and consumers' purchase intentions: An empirical investigation. Journal of Foodservice Business Research, 19(5), 497-513. https://doi.org/10.1080/15378020.2016.1189744

Glanz, K., Rimer, B. K., \& Viswanath, K. (Eds.). (2008). Health behavior and health education: Theory, research, and practice. Londob: John Wiley \& Sons.

Gray, N. J., Klein, J. D., Noyce, P. R., Sesselberg, T. S., \& Cantrill, J. A. (2005). Health information-seeking behaviour in adolescence: the place of the internet. Social Science $\mathcal{E}$ Medicine, 60(7), 1467-1478. https://doi.org/10.1016/j.socscimed.2004.08.010.

Guilford, J. P. (1973). Fundamental statistics in psychology and education. New York: McGrawHill.

Gunawan, I. A., \& Nurrachmawati, A. (2017). Malaria in pregnancy: A qualitative study on health belief model in Muara Wahau East Kalimantan. Jurnal Kesehatan Masyarakat Andalas, 11(2), 84-92.

Hale, T. M., Cotten, S. R., Drentea, P., \& Goldner, M. (2010). Rural-urban differences in general and health-related internet use. American Behavioral Scientist, 53(9), 1304-1325.

Hochbaum, G., Rosenstock, I., \&amp; Kegels, S. (1952). Health belief model. United States Public Health Service. Retrieved from http://www.infosihat.gov.my/infosihat/artikelHP/ bahanrujukan/HE_DAN_TEORI/DOC/Health\%20 Belief\%20Model.doc

Horgan, Á., \& Sweeney, J. (2012). University students' online habits and their use of the Internet for health information. CIN: Computers, Informatics, Nursing, 30(8), 402-408.

Jabson, J. M., Patterson, J. G., \& Kamen, C. (2017). Understanding health information seeking on the Internet among sexual minority people: Cross-sectional analysis from the health information national trends survey. JMIR Public Health and Surveillance, 3(2), e39.

Jamal, A., Khan, S. A., AlHumud, A., Al-Duhyyim, A., Alrashed, M., Shabr, F. B., \& Qureshi, R. (2015). Association of online health information-seeking behavior and self-care activities among type 2 diabetic patients in Saudi Arabia. Journal of Medical Internet Research, 17(8), e196.

Jones, C. L., Jensen, J. D., Scherr, C. L., Brown, N. R., Christy, K., \& Weaver, J. (2015). The Health Belief Model as an explanatory framework in communication research: exploring parallel, serial, and moderated mediation. Health Communication, 30(6), 566-576. https://doi.org/10.1080/10410236.2013.873353

Joseph, G., Burke, N. J., Tuason, N., Barker, J. C., \& Pasick, R. J. (2009). Perceived susceptibility to illness and perceived benefits of preventive care: An exploration of behavioral theory constructs in a transcultural context. Health Education \& Behavior, 36(5_suppl), 71S- 90S.

Kim, J., \& Park, H. A. (2012). Development of a health information technology acceptance model using consumers' health behavior intention. Journal of Medical Internet Research, 14(5), e133.

Lau, J. T., Gross, D. L., Wu, A. M., Cheng, K. M., \& Lau, M. M. (2017). Incidence and predictive factors of Internet addiction among Chinese secondary school students in Hong Kong: A longitudinal study. Social Psychiatry and Psychiatric Epidemiology, 52(6), 657-667. 
Lee, C. Y., Ting, C. C., Wu, J. H., Lee, K. T., Chen, H. S., \& Chang, Y. Y. (2018). Dental visiting behaviours among primary schoolchildren: Application of the health belief model. International Journal of Dental Hygiene, 16(2), e88-e95.

Li, Y., Wang, X., Lin, X., \& Hajli, M. (2018). Seeking and sharing health information on social media: A net valence model and cross-cultural comparison. Technological Forecasting and Social Change, 126, 28-40.

Malaysian Communication and Multimedia Commission. (2017). Intenet user survey 2017 (1823 - 2523). Malaysian Communications and Multimedia Commission. http://www.mcmc. gov.my

Mansor, M., \& Harun, N. Z. (2014). Health issues and awareness, and the significant of green space for health promotion in Malaysia. Procedia - Social and Behavioral Sciences, 153, 209220. https://doi.org/10.1016/j.sbspro.2014.10.055

Marcolino, M. S., Oliveira, J. A. Q., D’Agostino, M., Ribeiro, A. L., Alkmim, M. B. M., \& Novillo-Ortiz, D. (2018). The impact of mHealth interventions: systematic review of systematic reviews. JMIR mHealth and $u$ Health, 6(1), e23.

Marton, C., \& Choo, C. W. (2012). A review of theoretical models of health information seeking on the web. Journal of Documentation, 68(3), 330-352.

McWhirter, J. E., \& Hoffman-Goetz, L. (2016). Application of the health belief model to US magazine text and image coverage of skin cancer and recreational tanning (2000-2012). Journal of Health Communication, 21(4), 424-438.

Mills, A. \& Todorova, N. (2016). An integrated perspective on factors influencing online healthinformation seeking behaviours. In Australasian Conference on Information Systems, 5-7 Dec 2016. Wollongong.

Mohd-Nor, R., Chapun, T. E., \& J. Wah, C. R. (2013). Malaysian rural community as consumer of health information and their use of ICT. Malaysian Journal of Communication, 29(1), 161-177.

Mokhtar, I. A. (2009). Medical and health information seeking among Singapore youths: An exploratory study. Singapore Journal of Library E Information Management, 38, 49-76.

Montagni, I., Cariou, T., Feuillet, T., Langlois, E., \& Tzourio, C. (2018). Exploring digital health use and opinions of university students: Field survey study. JMIR mHealth and uHealth, 6(3), e65.

Muhamad, M., Afshari, M., \& Mohamed, N. A. (2011). Internet use and breast cancer survivors. Turkish Online Journal of Educational Technology-TOJET, 10(4), 241-247.

Musaiger, A., \& Kalam, F. (2014). Dietary habits and lifestyle among adolescents in Damascus, Syria. Annals of Agricultural and Environmental Medicine, 21(2), 416-419. https://doi.org/10.5604/1232-1966.1108616

Orlu, A. D., Imeh, K. D., \& Okike, B. I. (2016). Communication in information seeking behaviour. Library Philosophy and Practice, 1412, 1-58.

Osei Asibey, B., Agyemang, S., \& Boakye Dankwah, A. (2017). The internet use for health information seeking among Ghanaian university students: A cross-sectional study. International Journal of Telemedicine and Applications, 2017, 1-9. https://doi. org/10.1155/2017/1756473 
Oude Ophuis, P. A. M. (1989). Measuring health orientation and health consciousness as determinants of food choice behavior: Development and implementation of various attitudinal scales. In G. J. Avlonitis, N. K. Papavasiliou, \& A. G. Kouremenos (Eds.), Marketing thought and practice in the 1990's EMAC XVIII (pp. 1723-1725). Athens: Athens School of Economics and Business.

Painter, J. E., Plaster, A. N., Tjersland, D. H., \& Jacobsen, K. H. (2017). Zika virus knowledge, attitudes, and vaccine interest among university students. Vaccine, 35 (6), 960-965.

Park, M. J., Scott, J. T., Adams, S. H., Brindis, C. D., \& Irwin, C. E. (2014). Adolescent and young adult health in the United States in the past decade: little improvement and young adults remain worse off than adolescents. Journal of Adolescent Health, 55 (1), 3-16.

Plaster, A. N., Painter, J. E., Tjersland, D. H., \& Jacobsen, K. H. (2018). University students' knowledge, attitudes, and sources of information about Zika virus. Journal of Community Health, 43 (4), 647-655.

Robison-Chadwell, A. (2017). U.S. Young adults STDs, risk perception, risk behaviors, and health information seeking [Unpublished doctoral dissertation]. Walden University.

Robson, A., \& Robinson, L. (2015). The information seeking and communication model. Journal of Documentation, 71(5), 1043-1069. https://doi.org/10.1108/jd-01-2015-0023

Rosenstock, I.M. (1974). Historical Origins of the Health Belief Model. Health Education Monographs, 2(4), 328-335. http:s://doi.org/10.1177/109019817400200403

Senkowski, V., \& Branscum, P. (2015). How college students search the internet for weight control and weight management information: An observational study. American Journal of Health Education, 46(4), 231-240.

Sharif, S. P., Ahadzadeh, A. S., \& Wei, K. K. (2018). A moderated mediation model of internet use for health information. Journal of Social Sciences (COESERJ-JSS), 4(1), 611-625.

Sheng, X. \& Simpson, P. M. (2015). Health care information seeking and seniors: Determinants of internet use. Health Marketing Quarterly, 32(1), 96-112.

Sinclair, M., Lagan, B. M., Dolk, H., \& McCullough, J. E. (2018). An assessment of pregnant women's knowledge and use of the Internet for medication safety information and purchase. Journal of Advanced Nursing, 74(1), 137-147.

Suki, N. M. (2013). Students' dependence on smart phones. Campus-Wide Information Systems, 30(2), 124-134.

Suggs, S. L., Cowder, E. J., \& Noll, D. (2010). Health information seeking behavior of young educated Hispanic women. American Journal of Health Studies, 25(4), 186-195.

Taber, K. S. (2018). The use of Cronbach's alpha when developing and reporting research instruments in science education. Research in Science Education, 48 (6), 1273-1296. https:// doi.org/10.1007/s11165-016-9602-2.

Thackeray, R., Crookston, B. T., \&; West, J. H. (2013). Correlates of health-related social media use among adults. Journal of Medical Internet Research, 15(1). https://doi.org/10.2196/ jmir.2297.

Thomas, S., Beh, L., \& Nordin, R. B. (2011). Health care delivery in Malaysia: changes, challenges and champions. Journal of public health in Africa, 2 (2), e23. https://doi. org/10.4081/jphia.2011.e23

Twigg, O. C., \& Byrne, D. G. (2015). Perceived susceptibility to addiction among adolescent smokers. Journal of child E Adolescent Substance Abuse, 24(5), 235-242. 
Usher, W., Gudes, O., \& Parekh, S. (2016). Exploring the use of technology pathways to access health information by Australian university students: a multi-dimensional approach. Health Information Management Journal, 45 (1), 5-15.

Valera, P., Lian, Z., Brotzman, L., \& Reid, A. (2018). Fatalistic cancer beliefs and information seeking in formerly incarcerated African-American and Hispanic men: Implications for cancer health communication and research. Health Communication, 33(5), 576-584.

Wade, J. M. (2018). “Doing difference” and fast food consumption: Patterns among a sample of White and African American emerging adults. Journal of Racial and Ethnic Health Disparities, 5(2), 398-409.

Wang, J., Mann, F., Lloyd-Evans, B., Ma, R., \& Johnson, S. (2018). Associations between loneliness and perceived social support and outcomes of mental health problems: $a$ systematic review. BMC Psychiatry, 18(1), 1-16.

Watkins, J. O. T. A., Goudge, J., Gómez-Olivé, F. X., \& Griffiths, F. (2018). Mobile phone use among patients and health workers to enhance primary healthcare: A qualitative study in rural South Africa. Social Science \& Medicine, 198, 139-147.

Wong, C. K., Yeung, D. Y., Ho, H. C., Tse, K. P., \& Lam, C. Y. (2014). Chinese older adults' Internet use for health information. Journal of Applied Gerontology, 33(3), 316-335.

Yilma, T. M., Inthiran, A., Reidpath, D., \& Orimaye, S. O. (2017). Health Information seeking and its associated factors among university students: A case in a middle-income setting. In Pacific Asia Conference on Information Systems 2017 Proceedings, Langkawi, Malaysia. http:// aisel.aisnet.org/pacis2017/265

Yin, M., Luo, X. R., Xu, X., \& Li, Q. (2018, January). Why patients switch help from online to offline: An empirical investigation of emotions and effects of cognitions. In Proceedings of the 51st Hawaii International Conference on System Sciences.

Yoo, E., \& Robbins, L. S. (2008). Understanding middle-aged women's health information seeking on the web: A theoretical approach. Journal of the American Society for Information Science and Technology, 59(4), 577-590.

Yun, E. K., \& Park, H. A. (2010). Consumers' disease information-seeking behaviour on the Internet in Korea. Journal of Clinical Nursing, 19(19-20), 2860-2868.

Zahra, F., Hussain, A., \& Mohd, H. (2016, August). Usability factors of mobile health application for chronic diseases. AIP Conference Proceedings, 1761(1), 020108). https:// doi.org/10.1063/1.4960948

Zhou, X., \& Krishnan, A. (2019). What predicts exercise maintenance and well-being? Examining the influence of health-related psychographic factors and social media communication. Health communication, 34(6), 589-597. 